\title{
Frank Douglas
}

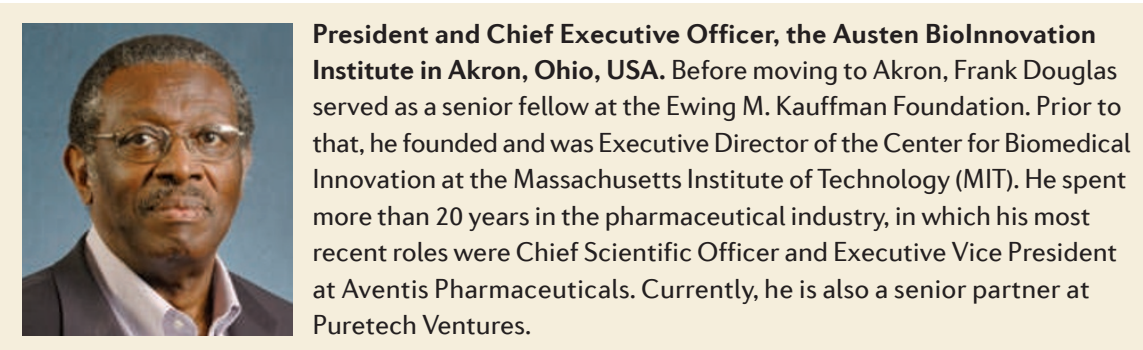

What attracted you to take your current position at the Austen BioInnovation Institute in Akron?

First of all, for me, the Institute in Akron is unprecedented in the sense that I have not seen another situation in which five institutions - three hospitals, a medical school and the university - and the city and the state government, as well as a large philanthropic organization, have come together with the common purpose of improving both the health and the economy of a region.

The second thing that impressed me when I first visited the institute was that the leaders of the five institutions had a common vision and purpose. When I met with over 60 physicians, scientists, nurses and administrators who had been working together in cross-institutional teams to organize the five centres of the institute, it was clear that they also shared that vision. I found it impressive because it is one thing for leaders to get together and share a common purpose, and another when they are able to convince the professionals (who will have to do the work) to deliver that vision.

The third thing is the desire to leave a legacy. When I am gone, people may not remember Frank Douglas or the teams with which I work, but the innovations we develop could have a lasting impact. The centres are focussed on providing health-care systems that leverage the strengths of the biomaterials research in the university, orthopaedics in the hospital and musculoskeletal biology in the medical school. With these teams, there is a real possibility of achieving innovations that will benefit patients, and hence the legacy.

Another component is entrepreneurship. When it comes to translating research findings into potential products, an entrepreneurial spirit needs to exist to make that translation happen. Therefore, the institutes are also focussed on spin-off companies for potential commercialization, adding to employment in the region.

What experiences from your previous roles do you think will be most valuable?

Having spent many years leading large global R\&D organizations - particularly multinational organizations in which one has to bring scientists from different perspectives and countries to work together - I gained experience that will be useful in guiding these institutions as they collaborate within the pre-competitive space. Also, when I founded the Center for Biomedical Innovation at MIT, we brought together the government, industry, MIT and Harvard to discuss ways of improving innovation of new therapies and devices. So that experience could also be useful. Finally, I have spent the past 2 years at the Kauffman Foundation as a senior fellow looking at entrepreneurship, entrepreneurial behaviour and how you stimulate it. I have also applied this in a practical sense as a senior partner at Puretech Ventures, where we look for ideas and intellectual property in academia and seed them as companies. So all of these things have come together, and I will be able to draw on those experiences, but also learn from this new

\section{The tough problems} require holistic, multidisciplinary approaches so that scientists from different backgrounds can enrich each other's thinking. experience. This is like the Mount Everest of medical and social transformation. It will not be easy but we have great Sherpas in the base camp, so I am delighted to be a part of it!

What types of unmet needs do you envisage addressing at the institute, and what types of innovative products do you expect to develop? We are focussing on leveraging the biomaterials strength of the University of Akron for orthopaedics and wound healing. For example, there is a need to find materials that can be good matrices for the healing of bones that not only are biodegradable but can also make good scaffolds in which one can impregnate bone-morphogenic proteins and other growth factors to induce bone growth. From the structural side, we have made a lot of progress in developing weight-bearing polymers that can be used for prostheses, replacement joins and for disc disease, but they can be improved. For example, the different properties that nanotechnologies can induce in materials will lead to improved prostheses or delivery of drugs. With regard to wound healing there are many possibilities, particularly in acute and chronic wounds, such as to how to improve scarring of wounds. We are looking at matrices that are biodegradable and contain materials that stimulate cells, such as fibroblasts or epidermal cells, to form the right skin structure. These are the kinds of challenges we will address.

What do you think are the major scientific challenges of developing such products and how will the institute address them? Over many years, I have come to the conclusion that we have relatively good symptomatic solutions for the 'low-hanging fruit', whereas the tough problems require holistic, multidisciplinary approaches so that scientists from different backgrounds can enrich each other's thinking. The major scientific challenge is to find solutions to these tough problems. The various centres that are being developed at the institute (the Center for Biomaterials and Medicine, the Medical Device Development Center, the Center for Clinical Trials, the Center for Health Care Training and the Community Outreach to the Medically Underserved), will make such a holistic, multidisciplinary approach possible. 